\title{
Two Years and Change: Building a Sustainable Culture of User Focused Assessment
}

\author{
Katy O'Neill, Loyola \\ Loyola University, USA
}

\begin{abstract}
As part of the transformation initiated by the current director, senior leadership at a mid-size academic library made a commitment to assessment as a tool to document success, support lean start-up operations, and inform decision-making. The strategy included hiring a two-year, term-limited librarian in the summer of 2016 to focus on assessment and act as the change champion, building capacity within the staff. In the last two years, the library assessment culture has been recast to an environment where staff uses assessment in planning and decision-making. After documenting the library's assessment environment in a status report, the assessment librarian and library administration developed a plan to stabilize the data-gathering infrastructure, implement best practices and standards, and build needed skills in survey design, data visualization, and other areas. Kotter and Schlesinger, in their 1979 landmark article, "Choosing Strategies for Change," suggested six methods for dealing with change resistance. The library administration used three of these approaches-education and communication, participation and involvement, and facilitation and support-to engage staff in assessment and build a sustainable culture of user-focused assessment. These change management approaches may be applicable to all libraries. Today supervisors and staff recognize that data and assessment are an integral part of their ongoing work and consistently use assessment in developing user-focused services.
\end{abstract}

\section{Introduction}

Since late 2012, under the leadership of the Loyola Notre Dame Library's fourth director, a transformation initiative to align the library's purpose with the educational missions of the two universities it serves and transition the library into an innovative learning center that adapts to users' changing needs for physical space, information, and technology is underway. To further support and accelerate the transformation process, in 2016, library leadership invested in a two-year, term-limited assessment and usability librarian to support the development of a culture of user-focused assessment. This approach allowed the mid-size academic library to invest in assessment and leverage Kotter and Schlesinger's strategies for change to develop infrastructure, implement best practices, and develop staff skills that are today integral to the ongoing work to support the research, teaching, and learning priories of faculty and students at Loyola University Maryland and Notre Dame of Maryland University.

\section{Literature Review}

Kotter and Schlesinger's landmark article originally published in 1979, "Choosing Strategies for Change," provided leaders with an initial framework to respond to an accelerating rate of environmental change. ${ }^{1}$ Specifically, Kotter and Schlesinger articulate six approaches to facilitate change depending on an assessment of need relative to organization culture and context: education and communication; participation and involvement; facilitation and support; negotiation and agreement; manipulation and co-optation; and explicit and implicit coercion. ${ }^{2}$ The article's flexible and adaptive approach to countering resistance to change is built upon in subsequent works on change by Kotter, including his Eight Stage Process of Creating Major Change outlined in the book Leading Change published in 1996. This model was developed by Kotter after years of observing change efforts at over 100 companies and the application of this model have proven successful overtime. ${ }^{3}$

Meredith Farkas' 2013 article, "Building and Sustaining a Culture of Assessment: Best Practices for Change Leadership," initiates the discussion of applying Kotter's work on change, specifically the Eight Stage Process of Creating Major Change, to "create a culture of assessment that is embedded in the organizational culture." Importantly, Farkas defines a culture of assessment in academic libraries as follows: 
1. Assessment becomes the norm and a valued part of the planning process;

2. Library staff engage with users to learn directly about preferences and needs versus making assumptions about users' interests;

3. Assessment data including direct feedback from users is used to improve customer service and experiences;

4. A culture of assessment is demonstrated by a willingness of library staff to change both behaviors and attitudes to deliver a high quality customer experience. ${ }^{5}$

Ultimately, Farkas challenged academic libraries to consider applying Kotter's Eight Stage Process of Creating Major Change to facilitate the development of a culture of assessment within libraries. She further challenged libraries to share their experiences with the model via case studies in literature to assess the value of this approach to change management more fully. Carter was the first to respond to Farkas' challenge and outlined Kotter's Eight Stage Process as follows:

1. Establish a sense of urgency

2. Create the guiding coalition

3. Develop a vision and strategy

4. Communicate the change vision

5. Empower employees for broad-based action

6. Generate short-term wins

7. Consolidate gains and produce more change

8. Anchor new approaches in the culture ${ }^{6}$

Carter applied the model to integrate information literacy assessment into Auburn University Libraries' instruction program and found it successful for facilitating change at the department level, however, noting the limitation of the departmental approach for enabling institutional change. ${ }^{7}$ Carter also articulated an evaluation of the change in the culture of assessment, noting examples of behavior change while also articulating a more realistic picture that not everyone doing assessment will necessarily "like" it. ${ }^{8}$ Hackman of the University of Maryland's McKeldin Library also demonstrated a case study that successfully applied Kotter's model of change on the reorganization of a Resource Sharing and Access Services Department. ${ }^{9}$ Fox and Keisling found Kotter's model of change effective in supporting the transformation of services, staffing, and spaces at University of Louisville Libraries. ${ }^{10}$ Wheeler and Holmes found similar success in their respective medical libraries at Will Cornell Medical College and Northwestern University Feinberg School of Medicine. ${ }^{11}$ These case studies demonstrate a foundation of the successful application of Kotter's approach to change management in academic libraries. However, these case studies represent findings for application of Kotter's Eight Stage Process of Creating Change in large or specialized academic libraries.

This paper will examine the success of a simplified application of Kotter's work to facilitate the adoption of a culture of assessment in a mid-size independent academic library. A retrospective review of the development of a culture of assessment by the Loyola/Notre Dame Library (LNDL) reveals that Kotter and Schlesinger's landmark article originally published in 1979, "Choosing Strategies for Change," provides a simplified approach for understanding the change process that may be applicable to all libraries. Specifically, LNDL's 
administration used three of Kotter and Schlesinger's approaches-education and communication, participation and involvement, and facilitation and support-to engage staff in assessment and build a sustainable culture of user-focused assessment to transform the customer experience. ${ }^{12}$

\section{Background and Institutional Context}

LNDL is one of two independent academic libraries in the United States and supports the educational missions of two universities located in northwestern Baltimore City: Loyola University Maryland (Loyola) and Notre Dame of Maryland University (Notre Dame). Loyola University Maryland, a member of the Association of Jesuit Colleges and Universities, is recognized for excellence in teaching and learning for the whole person in undergraduate and graduate programs rooted in the liberal arts. Notre Dame of Maryland University is a leader in the education of women and non-traditional students, including an undergraduate women's college; a college of adult undergraduate studies; and Schools of Education, Nursing and Pharmacy. The library serves a total student population of over 6,100 FTE.

In 2008, LNDL completed an extensive renovation of the library's 125,000-square-foot building. Since the arrival of the library's fourth director, Barbara Preece, in 2012, the library has been partnering with both universities to transform into an innovation learning center that responds flexibly to users' changing needs for access to space, information, and technology to support their research, teaching, and learning. Since 2015, the library joined two consortia: the Eastern Academic Scholar's Trust (EAST), a print initiative guaranteeing access to 6 million volumes through resource sharing, and the University System of Maryland and Affiliated Institutions (USMAI), which provides users access to over 9 million items through a shared integrated library system with 17 member libraries. In the fall of 2018, the library opened the doors on the newly renovated digital commons featuring access to the library's Innovation Station Makerspace, the Collaboratory in the library, an active learning classroom, a recording studio, the Copyright Information Center, and new group study spaces. Finally, adaptive technology was mainstreamed throughout the library in partnership with disability service departments from both universities, expanding access for disabled users.

A cornerstone of the success of these transformation initiatives is LNDL's growing institutional capacity to engage users through assessment to better understand their needs, interests, and preferences and use this data to inform decision-making. Library staff began by tapping into a historical commitment to deliver highquality customer service and learned to analyze and present data in one-page proposals to recommend ideas to library administration to improve user experience. To further support staff in the development of a culture of assessment, library administration also hired a two-year, term-limited librarian in the summer of 2016 to focus on assessment and act as the change champion to continue building capacity within the staff. During this two-year assignment, the assessment and usability librarian documented the library's current assessment environment in a status report, developed a plan with library administration and staff to stabilize data gathering infrastructure, identified and implemented best practices and standards, and built needed skills in survey design and data visualization. Ultimately, LNDL's assessment culture has been recast as an environment where staff regularly uses assessment in planning and decision-making to improve the user experience.

\section{Kotter and Schlesinger Change Methods Applied}

Kotter and Schlesinger's landmark article originally published in 1979, "Choosing Strategies for Change," recommends six methods for dealing with resistance to change with method selection based on factors like urgency of change and the type of resistance anticipated. ${ }^{13}$ When time is not an immediate factor, the first three of Kotter and Schlesinger's change approaches-education and communication, participation and involvement, and facilitation and support-can successfully be used to engage people in the process of change as follows: ${ }^{14}$ 


\begin{tabular}{|l|c|c|}
\hline Change Approach & \multicolumn{1}{|c|}{ Commonly Used When } & \multicolumn{1}{c|}{ Advantages } \\
\hline $\begin{array}{l}\text { Education / } \\
\text { Communication }\end{array}$ & $\bullet \begin{array}{l}\text { Lack of information } \\
\text { Inaccurate information and } \\
\text { analysis }\end{array}$ & $\begin{array}{l}\text { Common understanding often } \\
\text { persuades people to help with } \\
\text { change implementation }\end{array}$ \\
\hline $\begin{array}{l}\text { Participation / } \\
\text { Involvement }\end{array}$ & $\bullet \begin{array}{l}\text { Change leaders lack information } \\
\text { to design the change } \\
\text { Power to resist exists }\end{array}$ & $\begin{array}{l}\text { Important information from all } \\
\text { levels is integrated into change } \\
\text { plan }\end{array}$ \\
& $\begin{array}{l}\text { Participation creates buy-in } \\
\text { and commitment to } \\
\text { implementing change }\end{array}$ \\
\hline $\begin{array}{l}\text { Facilitation / } \\
\text { Support }\end{array}$ & $\bullet \begin{array}{l}\text { Adjustment problems like fear of } \\
\text { being unable to acquire new skills } \\
\text { to support the change at root of } \\
\text { resistance }\end{array}$ & $\bullet \begin{array}{l}\text { Best method to identify and } \\
\text { address adjustment issues }\end{array}$ \\
\hline
\end{tabular}

A retrospective review of the development of a culture of assessment at LNDL over the past two years will be assessed by each of the three change approaches outlined above to provide other academic libraries with ideas to support their own assessment change initiatives.

\section{Education and Communication on Assessment at LNDL}

LNDL allocates funding to librarians for professional development on an annual basis. In addition, the library's director sponsors attendance at conferences, training sessions, and local programming for librarians and staff for strategic priorities as the budget permits. Developing institutional capacity for assessment is a priority of senior library leadership and a number of educational opportunities have been provided for all staff at LNDL. In 2015, LNDL hosted a workshop open to all staff members with Towson University Library and Johns Hopkins Libraries on assessment that was facilitated by OCLC's senior research scientist and director of user research, Lynn Silipigni Connaway. A user question, "If you had a magic wand," quickly became one of many assessment tips and strategies used by LNDL staff to assess users' preferences for space, information, and technology. LNDL used professional development funds to send the associate director, head of research and access services, and the new assessment and usability librarian to the 2016 Library Assessment Conference hosted in Arlington, Virginia to support the process of assessing the current state of assessment of LNDL. It was also an important resource for generating ideas for the development of LNDL data-gathering framework in use today. In 2018, LNDL sent as many librarians and staff who expressed interest to an Assessment in Action Workshop hosted by USMAI and ACRL Maryland and invited Dr. Martha Kyrillidou of Quality Metrics, LLC to present at a staff meeting on best practices in assessment as part of a larger consulting commitment to USMAI. These are but a few examples of LNDL's formal investment in education for staff of all levels on assessment. Communication and sharing of best practices around assessment is also encouraged informally in unit meetings and in regular one-on-ones with supervisors. Finally, top lessons learned from conference attendance by librarians and staff are consolidated and shared by a research and instruction librarian every few months. This has provided a low-lift, easy method to share best practices and standards in all areas of librarianship, including assessment while promoting a culture of continuous improvement.

\section{Participation and Involvement in Assessment at LNDL}

The hiring of the two-year-term assessment and usability librarian was critical for providing additional capacity for a mid-size academic library to engage staff at all levels in the development of a culture of assessment. This librarian allowed the conversation to occur on a peer-to-peer basis to gain traction. The librarian spent time speaking with librarians and staff in all units of the library to develop a deep understanding of the strengths and opportunities of the current state of assessment at LNDL in 2016. This dialog and information sharing was critical for an accurate summary of what staff needed to improve datagathering infrastructure, clarify roles and responsibilities relative to assessment, identify opportunities to improve skills, and provide interested staff experiences with data visualization software like Tableau. The assessment and usability librarian also regularly attended department meetings to share updates on the 
project's progress over the course of the two-year assignment and developed a research guide on assessment and usability. This participative process created a new data-gathering framework that the library uses today to clearly define roles and responsibilities regarding data collection and reporting. The inclusive process of developing the data-gathering framework also provided the foundation for the assessment and usability librarian to act as a partner and consultant to enact change within each unit of the library. This feedback and spot training on topics of interest like developing effective Qualtrics surveys ensures that a culture of assessment has continued to evolve despite the end of the two-year-term assessment and usability librarian position in July of 2018.

\section{Facilitation and Support of Assessment at LNDL}

Providing staff the opportunity to practice skills with effective role modeling and mentoring from senior leadership is critical to the development of a mindset of assessment. As previously mentioned, LNDL uses one-page proposals to make recommendations to the library's director and senior leaders for innovation. Staff proposals were developed to recommend the launch of the Copyright Information Center in 2016, the integrations of reference and circulations desks into a single help desk in 2017, and the purchase of a mobile visualization wall in the library's new Digital Commons in 2018. These are just a few examples of proposals developed by staff that presented data in context and informed decision-making. The proposals are often two-sided and identify the customer experience that the recommendation is seeking to address. The proposals include assessment data, including visualized usage data, preference and interest data collected from users, and best practices from other comparable institutions to help support the recommended solution. As a result, library staff have become more effective at articulating user needs, using relevant data to make a case for change, and presenting persuasive recommendations to senior library leadership. Ultimately, this continual practice allows the fundamentals for assessment to integrate into day-to-day library operations and provides staff with the confidence to articulate the value they provide in their work to support the research, teaching, and learning of the two universities LNDL serves.

Encouraging participation in location, state and national conference by librarians and staff is another way that LNDL has supported librarians and staff in the use of assessment data to tell the story of how they are creating value for their users. A good example of this approach to skill- and confidence-building is LNDL's continued involvement in Towson University Library's Conference for Academic Libraries since it started in 2016. This local conference is particularly accessible as it is open to presentations and posters from librarians and staff. In 2018, interlibrary loan, research and instruction, and acquisitions units all did presentations or posters at the conference highlighting work done in their respective areas that highlighted assessment data. As skill and confidence levels have risen, we see librarians and staff seeking out opportunities to share information and present at local and national conferences more regularly.

\section{Conclusion: Assessing a Culture of Assessment at LNDL}

Reflecting on Farkas' features of a culture of assessment previously articulated, LNDL has integrated assessment into the library's operations, regularly solicits data from users to inform decision-making about existing and future plans, and uses this data as a core element of supporting the transformation of the library into an innovative learning center that adapts to users' needs in space, information, and technology. Behavior changes relative to assessment can be attributed to LNDL's focus on education and communication, participation and involvement, and facilitation and support that was accelerated in the past two years with the addition of the two-year-term accessibility and usability librarian position. As for changes in attitudes, Carter aptly articulates that there are nuances to be considered when "liking" assessment is considered. ${ }^{15}$ At LNDL, staff have a long-held dedication for delivering high quality customer service. A focus on assessment to support the innovation of the customer experience to allow staff to connect and engage with users and colleagues to expand on existing services is satisfying, and staff have expressed excitement in seeing users engage and benefit from changes implemented to date. This satisfaction and excitement is providing a strong foundation for a culture of assessment to continue to evolve and develop over time.

\footnotetext{
-Copyright 2019 Katy O’Neill
} 


\section{Notes}

1. Kotter and Schlesinger, "Choosing Strategies for Change," 130.

2. Kotter and Schlesinger, "Choosing Strategies for Change," 136.

3. Hackman, "Leading Change in Action," 2.

4. Farkas, "Building and Sustaining a Culture of Assessment," 14.

5. Farkas, "Building and Sustaining a Culture of Assessment," 15.

6. Carter, "Assessment and Change Leadership," 149.

7. Carter, "Assessment and Change Leadership," 160.

8. Carter, "Assessment and Change Leadership," 161.

9. Hackman, "Leading Change in Action," 1-27.

10. Fox and Keisling, "Build Your Program by Building Your Team," 526-539.

11. Wheeler and Holmes, "Rapid Transformation of Two Libraries," 276-281.

12. Kotter and Schlesinger, "Choosing Strategies for Change," 136.

13. Kotter and Schlesinger, "Choosing Strategies for Change," 137.

14. Kotter and Schlesinger, "Choosing Strategies for Change," 136.

\section{References}

Carter, Tori M. "Assessment and Change Leadership in an Academic Library Department: a Case Study." Reference Services Review 42, no. 1 (2014): 148-164. http://dx.doi.org/10.1108/RSR-05-2013-0028.

Farkas, Meredith Gorran. "Building and Sustaining a Culture of Assessment: Best Practices for Change Leadership.” Reference Services Review 41, no. 1 (2013): 1331. http://dx.doi.org/10.1108/00907321311300857.

Fox, Robert E and Bruce L. Keisling, "Build Your Program by Building Your Team: Inclusively Transforming Services, Staffing and Space.” Journal of Library Administration 56, no. 5 (2016): 526539. http://dx.doi.org/10.1080/01930826.2015.1105548.

Hackman, Timothy A. "Leading Change in Action: Reorganizing an Academic Library Department Using Kotter's Eight Stage Change Model.” Library Leadership \& Management 31, no. 2 (2017): 127. http://dx.doi.org/10.13016/M2XZ7B.

Kotter, John P. and Leonard A. Schlesinger. "Choosing Strategies for Change." Harvard Business Review, no. 86 (July-August 2008): 130-139.

Wheeler, Terrie R and Kristi L. Holmes, "Rapid Transformation of Two Libraries Using Kotter's Eight Steps of Change." Journal of the Medical Library Association 105, no. 3 (2017): 276-

281. http://dx.doi.org/10.5195/jmla.2017.97. 